\title{
Analisis Dan Pemetaan Kesesuaian Lahan Tanaman Anggur Di Kabupaten Buleleng Dengan Sistem Informasi Geografis
}

\author{
Made Agung Raharja ${ }^{\mathrm{a} 1}$ \\ a Program Studi Teknik Informatika, Universitas Udayana \\ Jimbaran Bali, Indonesia \\ ${ }^{1}$ made.agung@unud.ac.id
}

\begin{abstract}
Kabupaten Buleleng ini merupakan salah satu penghasil anggur di Bali yang biasa dikenal dengan julukan Anggur Buleleng. Pengalama beberapa periode sering terjadi buah anggur yang ditanam itu mengalami pembusukan, mati, hingga gagal panen hingga membuat penurunan produktivitas dan membuat para pembudidaya itu mengalami kerugian yang menyebabkan perekonomian daerah melemah. Sehingga digunakan solusi dengan suatu metode atau bantuan teknologi informasi salah satunya adalah dengan Sistem Informasi Geografis. Banyak permasalahan keruangan yang rumit, seperti kependudukan, pertanian, pemetaan wilayah yang menggunakan sistem informasi geografis untuk menyelesaikan masalah. Berdasarkan hasil penelitian dan pengolahan data yang dilakukan mengenai analisis dan perancangan sistem informasi geografis kesesuaian lahan untuk tanaman anggur di Kabupaten Buleleng, maka dapat disimpulkan bahwa : 1) Penelitian ini yaitu menganalisis, merancang, dan mengimplementasikan menggunakan aplikasi QGIS. 2) Persebaran tanaman anggur dikabupaten Buleleng mendapatkan hasil bahwa 6 kecamatan merupakan kategori S1 yaitu pada kecamatan Gerokgak, Buleleng, Seririt, Banjar, Kubutambahan, dan Tejakula. Jumlah kecamatan yang merupakan kategori S2 (sesuai) adalah sebanyak 2 kecamatan yaitu pada kecamatan Sukasada dan Sawan. Jumlah kecamatan yang merupakan kategori S3 (kurang sesuai) adalah sebanyak 1 kecamatan yaitu pada kecamatan Busungbiu.
\end{abstract}

Keywords: Anggur Buleleng, Sistem Informasi Geografis

\section{Pendahuluan}

Pulau bali merupakan salah satu tempat yang dijadikan destinasi wisata dunia saat ini. Banyak wisatawan lokal maupun mancanegara yang berkunjung ke Bali untuk menikmati keindahan alam di Bali. Salah satu daya tarik pulau Bali karena Bali merupakan penghasil buah tropis yang memiliki keanekaragaman buah buahan. Selain rasanya yang manis dan segar, buahbuahan juga bermanfaat karena menjadi sumber vitamin dan mineral dalam tubuh manusia. Salah satu buah yang kaya dengan vitamin dan mineral adalah buah anggur. Buah anggur ini banyak mengandung $130.67 \mathrm{mg} \mathrm{K}, 4.5 \mathrm{mg} \mathrm{Mg}, 0.07 \mathrm{mg} \mathrm{Zn}, 130.67 \mathrm{mg} \mathrm{K}, 0.07 \mathrm{mg} \mathrm{Zn} 0.09 \mathrm{mg}$ $\mathrm{Fe}$, dan $1.94 \mathrm{mg} \mathrm{Na}$ di dalam 100gram buah. Tidak itu saja, dalam buah anggur juga banyak mengandung vitamin-vitamin yaitu vitamin A, Vitamin C $43.79 \mathrm{mg} / 100 \mathrm{gram}$, vitamin B , dan vitamin E $0.16 \mathrm{mg} / 100 \mathrm{gram}$. (Julieta:2013). Buah anggur merupakan buah yang sudah banyak di gemari di Indonesia karena rasanya yang manis dan enak, bentuk menarik, hingga nilai gizi yang tinggi.

Kabupaten Buleleng merupakan suatu kabupaten yang terletak dibelahan utara pulau Bali berbentuk memanjang dari arah barat ke timur. Luas keseluruhan kabupaten Buleleng ini yaitu 136,588 hektar. Kabupaten ini memiliki 9 kecamatan yang terdiri dari kecamatan Busungbiu, kecamatan Gerokgak, Kecamatan Banjar, Kecamatan Kubutambahan, Kecamatan Seririt, Kecamatan Sukasada, Kecamatan Buleleng, Kecamatan Sawan dan Kecamatan Tejakula. Kabupaten Buleleng ini merupakan salah satu penghasil anggur di Bali yang biasa dikenal 
dengan julukan Anggur Buleleng. Selama ini masyarakat yang ada dikabupaten Buleleng dalam membudidayakan buah anggur tidak melihat karakteristik dan kebutuhan dari buah anggur tersebut dan hanya mengandalkan analisis daerah sekitar. Masyarakat belum mengetahui bahwa pengaruh tinggi daerah, kedalaman tanah suatu daerah, suhu, curah hujan, dan kondisi ph tanah jika ada di tempat lain akan menghasilkan anggur dengan kualitas yang berbeda. Sehingga sering terjadi buah anggur yang ditanam itu mengalami pembusukan, mati, hingga gagal panen hingga membuat penurunan produktivitas dan membuat para pembudidaya itu mengalami kerugian yang menyebabkan perekonomian daerah melemah.

Pada zaman yang modern ini, perkembangan teknologi di bidang sistem informasi semakin pesat. Sistem informasi yang berbasis komputer dapat digunakan untuk melakukan analisis data, mengintegrasikan berbagai data dan informasi. Melalui sistem informasi geografis yang mencakup informasi terkait lokasi, sebaran luas area, jenis sumber daya dapat diperoleh dengan cepat dan mudah. Banyak permasalahan keruangan yang rumit, seperti kependudukan, pertanian, pemetaan wilayah yang menggunakan sistem informasi geografis untuk menyelesaikan masalah.(Budianto:2007).

\section{Metodelogi Penelitian}

\subsection{Studi Kepustakaan}

Dalam menunjang penelitian akan dilakukan studi pustaka dengan mempelajari beberapa buku teks, jurnal, dan karya ilmiah lainnya yang menunjang beberapa penelitian tentang analisis dan pemetaan kesesuaian lahan tanaman anggur di Kabupaten Buleleng dengan sistem informasi geografis

\subsection{Analisis dan Perancangan Sistem}

Tahap ini dilakukan perancangan disain sistem yang meliputi : Penetuan lokasi penelitian, pengumpulan data, proses perancangan sistem, dan disain input serta output.

\section{Penetuan Lokasi penelitian}

Penelitian dilakukan di kota Denpasar dan Kabupaten Badung Provinsi Bali serta data pada Badan Pusat Statistik (BPS) Provinsi Bali yang beralamat di Jl.Raya Puputan No. 1 Renon, Denpasar-Bali. BPS Kabupaten Buleleng, dan berbagai literatur terkait.

\section{Pengumpulan data}

Pengumpulan data atau tahap dokumentasi, yaitu mengadakan pembuatan dokumen yang akan menunjang aplikasi yang akan dibuat agar nantinya sistem bisa dikembangkan lebih lanjut. Dalam tahap ini adalah melakukan pengumpulan dan pengolahan data mengenai data Kesesuaian Lahan Tanaman Anggur Di Kabupaten Buleleng Dengan Sistem Informasi Geografis

\subsection{Implementasi}

Tahap ini dilakukan rancang bangun sistem ke dalam suatu perangkat lunak dari model yang telah di rancang pada tahap sebelumnya. Analisis Dan Pemetaan Kesesuaian Lahan Tanaman Anggur Di Kabupaten Buleleng Dengan Sistem Informasi Geografis ini mengunakan Quantum GIS versi 2.12 Lyon. Tahap Digitasi awal sampai output hasil secara keseluruhan mengunakan Aplikasi Quantum GIS.

\subsection{Pengujian dan Analisis sistem akhir.}

Pada tahap ini sistem yang telah di buat kemudian dilakukan pengujian sistem dengan menggunakan data yang telah diambil dan dengan survei ke masing-masing lokasi penelitian.

\section{Hasil Dan Pembahasan}

\subsection{Tahap Pengumpulan Data}

Setiap tanaman akan memiliki parameter lahan yang berbeda beda, karena karakteristik tanaman yang berbeda beda. Tanaman anggur yang berkualitas tinggi memiliki kriteria utama yang mempengaruhi kualitas buah yang akan dipanen nantinya. Parameter utama yang 
mempengaruhi tanaman anggur berdasarkan lahan tanamnya adalah ketinggian, ph tanah, dan suhu daerah. berikut ini adalah parameter tanaman anggur yang sesuai dengan kriteria agar mendapatkan kualitas buah yang tinggi.

Tabel 1. Parameter Kesesuain Lahan Tanaman anggur

\begin{tabular}{|l|l|l|l|l|}
\hline Parameter & S1 & S2 & S3 & N \\
\hline Ketinggian (Mdpl) & $1-300$ & $301-600$ & $601-900$ & $>901$ \\
\hline Ph & $5,5-7,3$ & $\begin{array}{l}5,2-5,5 \\
\text { \&\& } 7,3\end{array}$ & $\begin{array}{l}(<5,2 \& \& \quad> \\
8,0\end{array}$ & - \\
& & $-8,0$ & & \\
& & $\begin{array}{l}18-22 \\
\text { atau 14- } \\
16\end{array}$ & $\begin{array}{l}\text { 22-30atau } \\
12-14\end{array}$ & $\begin{array}{l}>30 \text { atau } \\
<12\end{array}$ \\
\hline Temperatur $\left({ }^{\circ}\right)$ & $16-18$ & & \\
& & & & \\
\hline
\end{tabular}

Tabel 2. Data Suhu, Ketinggian, dan Ph Tanah Perkecamatan Dikabupaten Buleleng

\begin{tabular}{|l|l|l|l|l|l|}
\hline No & $\begin{array}{l}\text { Nama } \\
\text { Kecamatan }\end{array}$ & $\begin{array}{l}\text { Luas } \\
\text { Wilayah }\end{array}$ & Suhu & $\begin{array}{l}\text { Ph } \\
\text { Tanah }\end{array}$ & Ketinggian \\
\hline 1 & Gerokgak & 356.57 & 28.3 & 5.5 & $0-499,9$ \\
\hline 2 & Seririt & 111.78 & 28.1 & 6.5 & $0-499,9$ \\
\hline 3 & Busungbiu & 196.62 & 28.9 & 5 & $500-999.9$ \\
\hline 4 & Banjar & 172.60 & 28 & 6.5 & $0-499,9$ \\
\hline 5 & Buleleng & 46.94 & 28.6 & 6.5 & $0-499,9$ \\
\hline 6 & Sukasada & 172.93 & 27.9 & 6.5 & 1000 \\
\hline 7 & Sawan & 92.53 & 28.5 & 6 & 1000 \\
\hline 8 & $\begin{array}{l}\text { Kubutamba } \\
\text { han }\end{array}$ & 118.24 & 28.4 & 6 & $0-499,9$ \\
\hline 9 & Tejakula & 97.68 & 28.1 & 5.5 & $0-499,9$ \\
\hline
\end{tabular}

Sumber : BPS Bali 2017

Data pada Tabel 2. adalah data luas wilayah, suhu, ph tanah, dan rata- rata ketinggian per kecamatan dikabupaten Buleleng. Dimana data tersebut yang akan digunakan untuk menganalisa kesesuaian lahan tanaman anggur yang ada dikabupaten buleleng.

Setelah data pada setiap kecamatan di dapatkan, langkah selanjutnya yaitu melakukan skoring dan pembobotan pada setiap parameter dan akan disesuaikan dengan kelas $\mathrm{S} 1, \mathrm{~S} 2$, S3 dan N. (Raharja,2016)

Tabel 3. Skoring Kelas

\begin{tabular}{|l|l|l|}
\hline No & Kategori & Skor \\
\hline 1 & Kelas S1 (Sangat Sesuai) & 3 \\
\hline 2 & Kelas S2 (Sesuai) & 2 \\
\hline 3 & Kelas S3 (Kurang Sesuai) & 1 \\
\hline 4 & Kelas N (Tidak Sesuai) & 0 \\
\hline
\end{tabular}


Setelah melakukan proses skoring pada setiap parameter, maka akan dilakukan proses pembobotan terhadap setiap parameter

Tabel 4. Nilai pembobotan parameter

\begin{tabular}{|l|l|l|}
\hline No & \multicolumn{1}{|c|}{ Kelas } & Bobot \\
\hline 1 & Baik & 3 \\
\hline 2 & Cukup & 2 \\
\hline 3 & Kurang & 1 \\
\hline
\end{tabular}

\subsection{Implementasi}

Setelah semua data terkumpul, kemudian dilakukan pengolahan data untuk mendapatkan informasi yang berhubungan dengan luas wilayah di Kabupaten Buleleng. Untuk memulai penggunaan Software Quantum GIS, klik ganda pada shortcut pada Quantum GIS Desktop (2.12 Lyon) di desktop. Pembuatan proyek baru dilakukan dengan memilih opsi Add Raster Layer. Kemudian pilih gambar yang akan di digitasi. Gambar dapat berformat .jpeg, .png, atau yang lainnya. (Astrini:2012).

Seluruh isi dari proyek tersebut saling terkait, namun masing-masing ini mempunyai fungsi dan peran yang berbeda. Berikut akan ditampilkan sedikit cara untuk mengolah data peta raster. Digitasi wilayah administrasi terkecil yaitu Kecamatan dari Kabupaten Buleleng dengan menggunakan polygon, sehingga menghasilkan seperti di bawah ini:

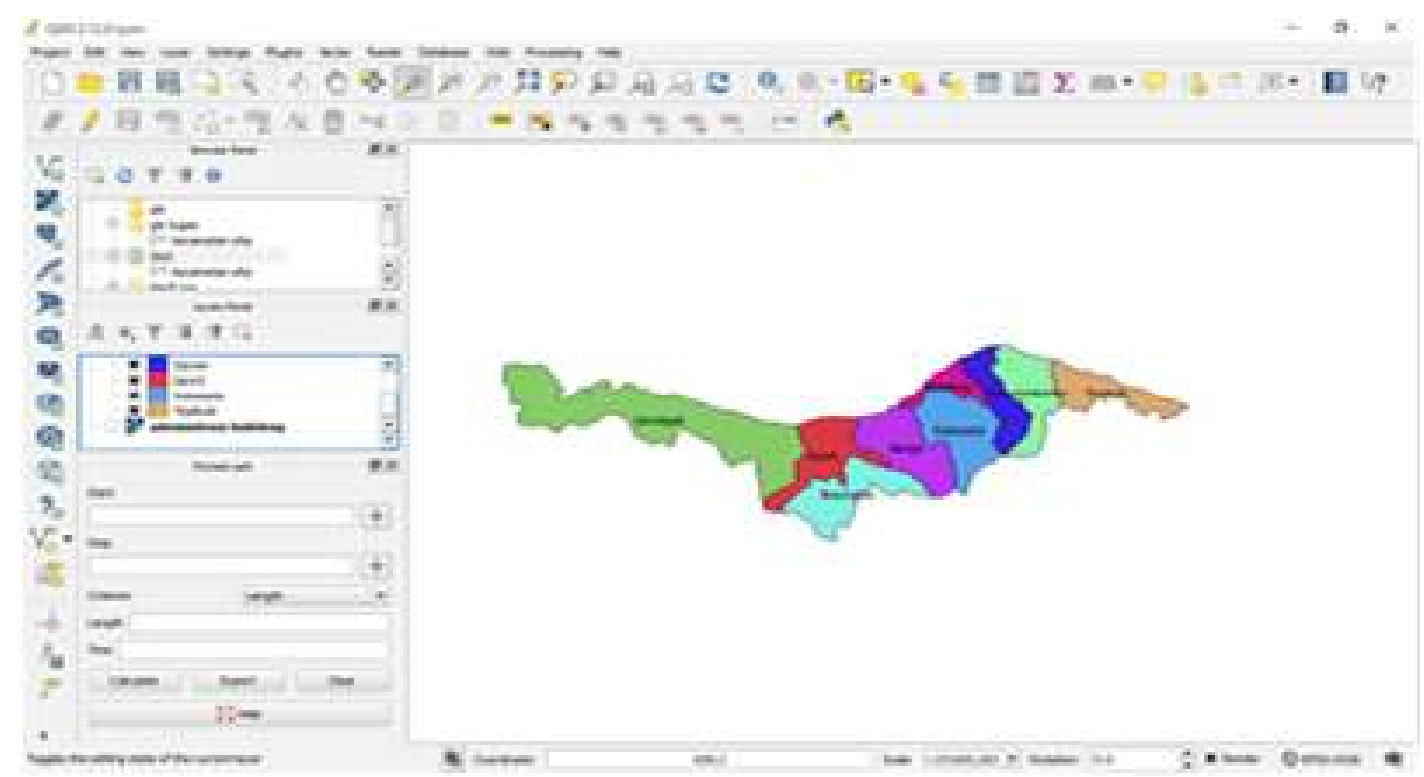

Gambar 1. Tampilan Data Spasial Kecamatan pada Kabupaten Buleleng 


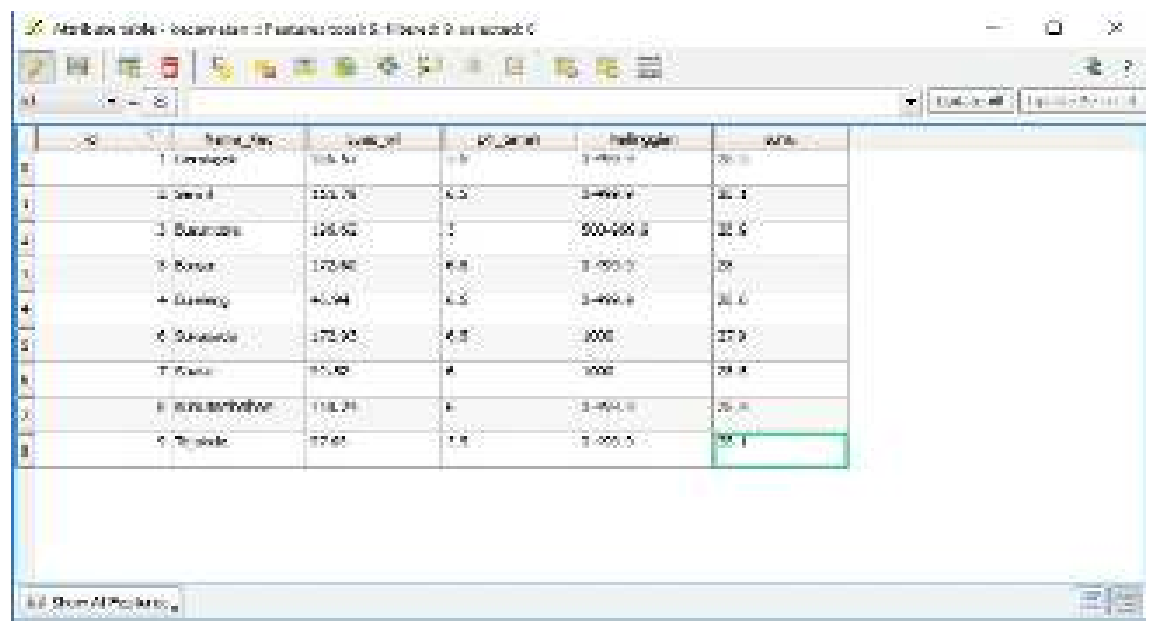

Gambar 2. Tabel Atribut Kecamatan

\subsection{Hasil}

Setelah selesai memasukkan nilai-nilai sesuai dengan table di atas maka dengan mengklik salah satu bagian dari wilayah kabupaten dengan Identify Features, maka akan muncul informasi yang terkait dengan kabupaten tersebut. Misalkan kita klik kabupaten Jembrana, maka akan muncul:

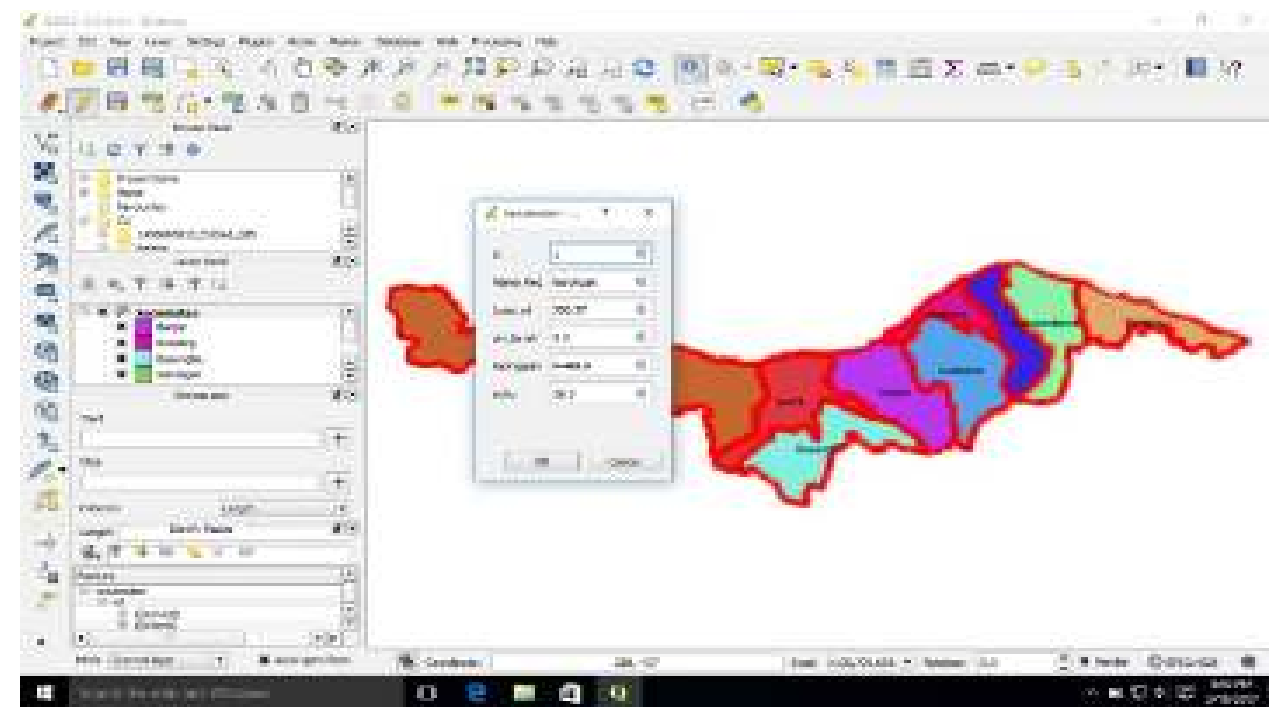

Gambar 3. Tampilan Data Spasial Kecamatan Gerokgak

\subsection{Pemberian skor dan Query}

Pada tahap ini akan dilakukannya pengelolaan data yang didapat dari berbagai sumber.

Data tersebut akan dimasukkan ke dalam basis data dan akan dilakukannya skoring pada setiap parameter di setiap kecamatan. Setelah skoring pada setiap kecamatan didapatkan, maka akan dilakukannya penjumlahan skor yang ada pada setiap kecamatan dikabupaten Buleleng. Berikut adalah data-data parameter kesesuaian lahan tanaman anggur pada kabupaten Buleleng yang sudah dilakukannya skoring dan penjumlahan skor. 
Tabel 5. Data-Data Setiap Kecamatan Di Kabupaten Buleleng Yang Telah Dilakukan Skoring

\begin{tabular}{|l|l|c|c|c|c|c|c|c|c|}
\hline No & $\begin{array}{l}\text { Nama } \\
\text { Kocamatan }\end{array}$ & $\begin{array}{l}\text { Luas } \\
\text { Wilayah }\end{array}$ & $\begin{array}{l}\text { Ph } \\
\text { Tanah }\end{array}$ & Ketinggian & Suhu & $\begin{array}{l}\text { Skor } \\
\text { Pb }\end{array}$ & $\begin{array}{l}\text { Skor } \\
\text { Ketinggian }\end{array}$ & $\begin{array}{l}\text { Skor } \\
\text { Suhu }\end{array}$ & $\begin{array}{l}\text { Total } \\
\text { skor }\end{array}$ \\
\hline 1 & Gerokguk & 365.57 & 5.5 & $0-499,9$ & 28.3 & 3 & 3 & 1 & 7 \\
\hline 2 & Seririt & 111.78 & 6.5 & $0-499,9$ & 28.1 & 3 & 3 & 1 & 7 \\
\hline 3 & Busumgbiu & 196.62 & 5 & $500-999,9$ & 28.9 & 1 & 1 & 1 & 3 \\
\hline 4 & Banjar & 172.93 & 6.5 & $0-499,9$ & 28 & 3 & 3 & 1 & 7 \\
\hline 5 & Buleleng & 45.95 & 6.5 & $0-499,9$ & 28.6 & 3 & 3 & 1 & 7 \\
\hline 6 & Sukassda & 172.93 & 6.5 & 1000 & 27.9 & 3 & 0 & 1 & 4 \\
\hline 7 & Sasazan & 92.52 & 6 & 1000 & 28.5 & 3 & 0 & 1 & 4 \\
\hline 8 & Kubutambahan & 118.24 & 6 & $0-499,9$ & 28.4 & 3 & 3 & 1 & 7 \\
\hline 9 & Tejakula & 97.65 & 5.5 & $0-499,9$ & 28.1 & 3 & 3 & 1 & 7 \\
\hline
\end{tabular}

Tabel 5 adalah tabel data-data parameter yang sudah dilakukan skoring dan penjumlahan skor. Untuk menentukan kesesuaian lahan ke dalam kategori S1, S2, S3, atau N akan dilakukannya pengelompokan skor berdasarkan ketentuan pada tabel 0.8.

Setelah didapatkannya skoring, total skor, dan pengelompokan skor terhadap data yang ada, maka akan dilanjutkan dengan melalukan query terhadap data tersebut untuk menentukan kesesuaian lahan untuk tanaman anggur pada kabupaten Buleleng.

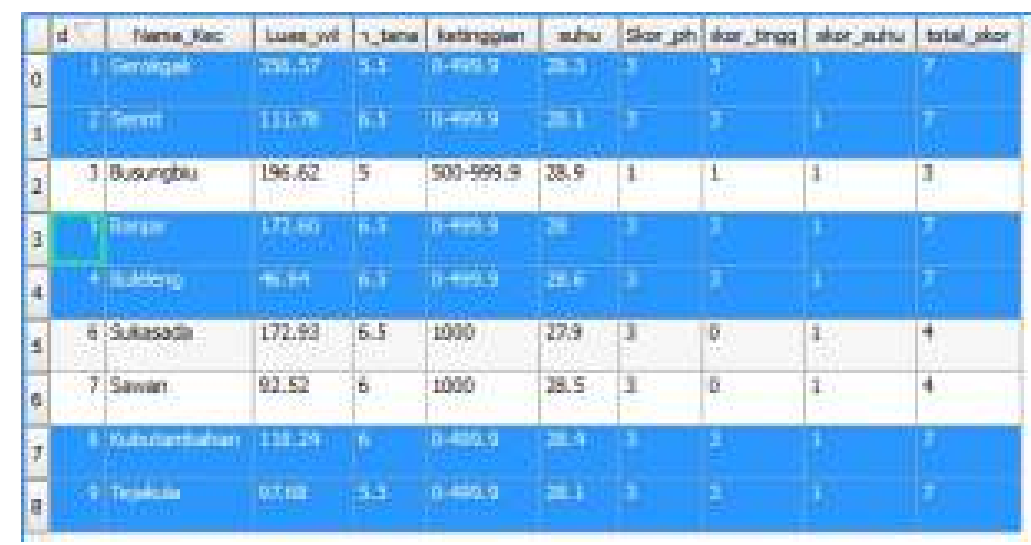

Gambar 4. seleksi kesesuaian lahan untuk kategori S1

Untuk kategori S1 memiliki total skor antara 7 sampai 9 dan tidak boleh ada parameter lahan yang bernilai 0 . Gambar 4 adalah potongan proses query untuk kesesuaian lahan untuk kategori S1. Sedangkan gambar 5 merupakan hasil seleksi dari query yang dituliskan dan mendapatkan 6 kecamatan yang termasuk kategori S1.

Setelah dilakukannya proses query seperti pada gambar 6. Maka pada data atribut akan otomatis menseleksi sesuai dengan query yang dituliskan. 


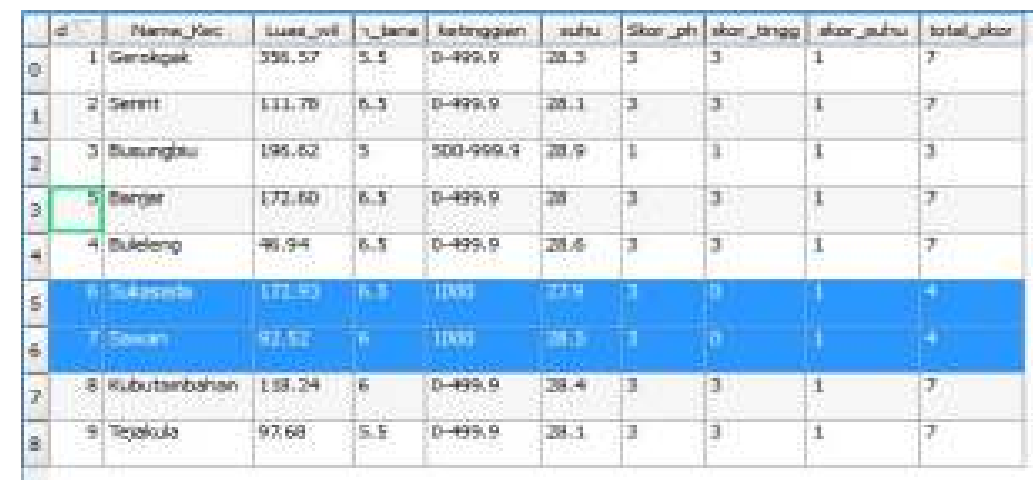

Gambar 5. seleksi kesesuaian lahan untuk kategori S2

Untuk kategori S2 memiliki total skor antara 4 sampai 6 dan boleh ada parameter lahan yang bernilai 0 . Gambar 5 adalah potongan proses query untuk kesesuaian lahan untuk kategori S2. Sedangkan gambar 09 merupakan hasil seleksi dari query yang dituliskan dan mendapatkan 2 kecamatan yang termasuk kategori S2.

Untuk kategori S3 memiliki total skor antara 2 sampai 3 dan boleh ada parameter lahan yang bernilai 0 . Gambar 10 adalah potongan proses query untuk kesesuaian lahan untuk kategori S3. Sedangkan gambar 11 merupakan hasil seleksi dari query yang dituliskan dan mendapatkan 1 kecamatan yang termasuk kategori S3. Maka pada data atribut akan otomatis menseleksi sesuai dengan query. Untuk kategori $\mathrm{N}$ memiliki total skor antara 0 sampai 1. Gambar 12 adalah potongan proses query untuk kesesuaian lahan untuk kategori S3. Sedangkan gambar 13 merupakan hasil seleksi dari query yang dituliskan, tapi tidak mendapatkan kecamatan yang termasuk kategori $\mathrm{N}$, karena kriteria lahan tidak termasuk ke dalam kategori $\mathrm{N}$.

\subsection{Pengujian dan Analisis Sistem Akhir}

Pada tahap ini sistem yang telah di buat kemudian dilakukan pengujian sistem dengan menggunakan data yang telah diambil dari berbagai sumber data.Sehingga didapatakan hasil kesesuaian lahan untuk tanaman Anggur di kabupaten Buleleng.

Setelah selesai melakukan proses query pada setiap kategori, maka akan mendapatkan hasil kesesuaian lahan tanaman anggur dikabupaten buleleng berdasarkan data perkecamatan. Berikut adalah hasil dari query berupa peta dengan pengelompokan kesesuaian lahan pada Gambar 6.

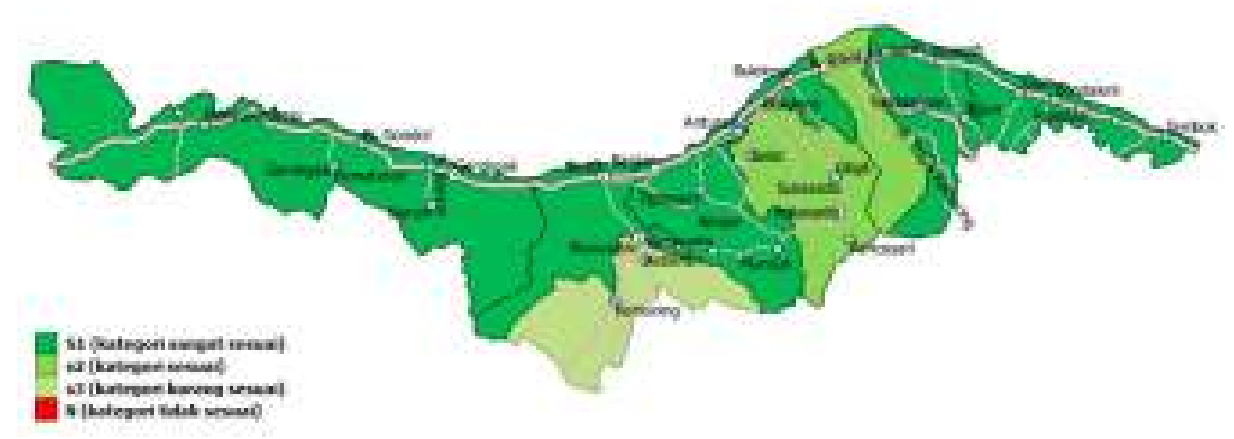


Gambar 6. Kesesuaian Lahan Tanaman Anggur Kabupaten Buleleng

Pada gambar 6 dari hasil query berdasarkan data-data perkecamatan, didapatkan hasil bahwa 6 kecamatan merupakan kategori S1 (sangat sesuai) yaitu pada kecamatan Gerokgak, Seririt, Banjar, Buleleng, Kubutambahan, dan Tejakula. Jumlah kecamatan yang merupakan kategori S2 (sesuai) adalah sebanyak 2 kecamatan yaitu pada kecamatan Sukasada dan Sawan. Jumlah kecamatan yang merupakan kategori S3 (kurang sesuai) adalah sebanyak 1 kecamatan yaitu pada kecamatan Busungbiu. Sedangkan untuk kategori N (tidak sesuai) tidak ada pada kabupaten Buleleng karena kriteria lahan tidak termasuk.

\section{Kesimpulan}

Berdasarkan hasil penelitian dan pengolahan data yang dilakukan mengenai analisis dan perancangan sistem informasi geografis kesesuaian lahan untuk tanaman anggur di Kabupaten Buleleng, maka dapat disimpulkan bahwa :

1. Penelitian ini yaitu menganalisis, merancang, dan mengimplementasikan menggunakan aplikasi QGIS Versi 2.12.0 melalui tahapan tahapan berupa pencarian data, input data spasial berupa peta dan data atribut, melakukan proses digitasi pada setiap kecamatan, pengolahan data hingga melakukan proses query hingga mendapatkan hasil kesesuaian lahan untuk tanaman anggur kabupaten Buleleng.

2. 2. Persebaran tanaman anggur dikabupaten Buleleng mendapatkan hasil bahwa 6 kecamatan merupakan kategori S1 yaitu pada kecamatan Gerokgak, Buleleng, Seririt, Banjar, Kubutambahan, dan Tejakula. Jumlah kecamatan yang merupakan kategori S2 (sesuai) adalah sebanyak 2 kecamatan yaitu pada kecamatan Sukasada dan Sawan. Jumlah kecamatan yang merupakan kategori S3 (kurang sesuai) adalah sebanyak 1 kecamatan yaitu pada kecamatan Busungbiu. Sedangkan untuk kategori N (tidak sesuai) tidak ada pada kabupaten Buleleng

\section{Daftar Pustaka}

[1] Astrini, R. \& Oswald, P. (2012, Agustus). Modul Pelatihan Quantum GIS Tingkat Dasar.

[2] Badan Pusat Statistik Bali, 2017, Bali Dalam Angka Tahun 2017, Provinsi Bali

[3] Budiyanto, Eko, 2007, Avenue Untuk Pengembangan Sistem Informasi Geografis, Andi, Yogyakarta

[4] Made Agung Raharja. 2016. Analisis Dan Perancangan Sistem Informasi Geografis Kesesuaian Lahan Untuk Tanaman Kopi Dikabupaten Buleleng

[5] Julieta Christy 2013,. Pengelolaan Tanaman Anggur (Vitis Vinifera) Di Pt Perkebunan Nusantara Xii. 
Jurnal IImu Komputer VOL. XI No. 2

p-ISSN: $1979-5661$

e-ISSN: 2622-321X

[6] Prahasta, Edy, 2009, Sistem Informasi Geografis Konsep-konsep Dasar, Informatika, Bandung. 